\title{
El patrimonio a través de la educación artística en la etapa de primaria
}

\author{
Heritage through Arts Education in Primary Stage
}

\author{
Olaia Fontal-Merillas \\ Universidad de Valladolid \\ ofontal@gmail.com
}

Recibido: 12 de enero de 2015

Aprobado: 28 de mayo de 2015

\section{Resumen}

El área de educación artística en el currículum de primaria ha estado ligada a la enseñanza del patrimonio en las tres últimas décadas y, seguida del área de Ciencias Sociales en sus diferentes denominaciones, ha sido la materia que más se ha ocupado del la enseñanza de nuestro legado cultural, desde la LOGSE, pasando por la LOE hasta la actual LOMCE. Sin embargo, con la última reforma educativa ha sufrido una pérdida de presencia que la sitúa como una materia prescindible, en tanto un alumno puede transitar por toda la etapa de Primaria sin recibir una sola hora de educación artística. En efecto, las CCAA y los centros, en el ejercicio de sus competencias (Artículo 3) pueden decidir no ofertarla o, aun ofertándola, puede no ser elegida de entre otras asignaturas específicas como Segunda Lengua Extranjera, Religión o Valores Sociales y Cívicos.

Por todo ello, proponemos un análisis del contenido de las tres grandes leyes generales de educación de las tres últimas décadas -LOGSE, LOE y LOMCE- examinando la presencia del patrimonio en la educación artística, para detectar los enfoques y concepciones subyacentes en los diferentes desarrollos curriculares. Todo ello nos situará ante un escenario, el presente, en el que podremos demandar la recuperación de contenidos o competencias perdidas, pero también promover el máximo aprovechamiento de las que sí se han incluido en el currículum vigente.

Palabras clave: educación artística, educación patrimonial, currículum, educación primaria, enseñanza forma.

Fontal-Merillas, O. (2016): El patrimonio a través de la educación artística en la etapa de primaria. Arte, Individuo y Sociedad, 28(1) 105-120

\begin{abstract}
Art education has been linked to the teaching of heritage in the curriculum of primary for the last three decades, as well as Social Sciences, the more implicated with cultural legacy subject, from LOGSE, through the LOE to the current LOMCE. However, with the latest educational reform, Art Education has lost importance, becoming an expendable matter, because a student can travel throughout the primary stage without receiving arts education. Indeed, the CCAA and centres may decide not to offer it or even, offering it, can not be chosen because the student must choose between arts, and other specific subjects such as Second Foreign Language, Religion and Social and Civic Values .

Therefore, we propose a content analysis of the three great general education laws of the past three decades -LOGSE,LOE andLOMCE-inrelation to thepresence of heritage in arts education, in ordertodetectapproaches and conceptions underlying the different curricular developments. This analysis will allow us demanding the recovery of content or lost skills, but also promote maximum development of those included in the curriculum. Keywords: art education, heritage education, curriculum, primary education, formal education.
\end{abstract}


Sumario: 1. La LOGSE: la dimensión actitudinal en el aprendizaje del patrimonio cobra presencia en la educación artística, 2. La LOE: hacia un modelo completo y complejo del patrimonio en educación artística, 3. La LOMCE: el patrimonio como contenido imprescindible en una asignatura prescindible, 3.1. El patrimonio en la asignatura optativa de educación artística, 3.2 El patrimonio cultural en las asignaturas troncales de Educación Primaria, 4. Conclusiones: el currículum y la rentabilidad de la educación patrimonial. Referencias.

Este artículo recoge resultados financiados por tres investigaciones:1. "Observatorio de Educación Patrimonial en España. Análisis integral del estado de la educación patrimonial en España” (EDU2012-37212), 2. "Educación Patrimonial en España: Consolidación, evaluación de programas e internacionalización del observatorio de educación patrimonial en España (OEPE)" (EDU2009-09679), financiadas por el Ministerio de Economía y Competitividad en el marco del programa de investigación fundamental no orientada. El tercer estudio se denomina 3. "Análisis del tratamiento del Patrimonio Cultural en la legislación educativa vigente" (IPCE061/126541), financiado por el Instituto del Patrimonio Cultural de España (Ministerio de Educación, Cultura y Deporte).

\section{La LOGSE: la dimensión actitudinal en el aprendizaje del patrimonio cobra presencia en la educación artística}

La LOGSE otorgó por primera vez un papel esencial al patrimonio en la etapa de Primaria, donde ya se mencionaba desde los objetivos generales la importancia de conocer el patrimonio cultural, participar en su conservación y mejora, respetar la actitud de interés y el respeto hacia el ejercicio de este derecho (LOGSE, 1990).

Este objetivo se desarrolló a través de las áreas curriculares de Conocimiento del Medio natural, social y cultural y de Educación Artística principalmente. Así, la enseñanza del Conocimiento del medio en la etapa de Educación Primaria tenía como cuarto objetivo analizar algunas manifestaciones de la intervención humana en el medio, valorar críticamente la necesidad y el alcance de las mismas y adoptar un comportamiento en la vida cotidiana acorde con la postura de defensa y recuperación del equilibrio ecológico y de conservación del patrimonio cultural. En esta misma área, en el bloque 10 de contenidos, encontrábamos el patrimonio referido en las actitudes como el respeto por el patrimonio cultural y natural (fiestas, artesanía, juegos, gastronomía, vestidos, vivienda, etc.) de la comunidad e interés por su mantenimiento y recuperación.

El área de Educación Artística también contemplaba el patrimonio ya desde su texto introductorio, donde se abordaba la dimensión social del patrimonio, entendiendo la producción artística como parte del mismo:

La producción artística forma parte del patrimonio cultural de un pueblo. En consecuencia, la educación artística ha de permitir el acceso a ese patrimonio cultural, a su aprecio, al reconocimiento de las variaciones en los criterios y en los estilos a lo largo del tiempo y de unas sociedades a otras (Real Decreto 1344, 1991).

Se pretendía, por tanto, abordar el patrimonio incidiendo en el acceso (derivado de las acciones vinculadas a la comunicación y difusión), pero también en el aprecio y la puesta en valor de la diversidad, entendida como riqueza, al referirnos a lo patrimonial. Los objetivos generales de la Educación Artística, recogían este planteamiento ofrecido en la introducción del área, y nuevamente insistían en el conocimiento y en el respeto hacia el patrimonio artístico: 
Objetivo 11. Conocer y respetar las principales manifestaciones artísticas presentes en el entorno, así como los elementos más destacados del patrimonio cultural, desarrollando criterios propios de valoración (Ibídem).

Esta orientación volvía a recogerse en el Bloque 8. Artes y Cultura, precisamente en los contenidos actitudinales, donde nos encontramos la primera referencia a la dimensión intercultural:

1. Valoración del patrimonio artístico (exposiciones, fiestas, danzas, artesanía) de la comunidad y respeto por sus manifestaciones.

2. Apertura a otras manifestaciones artísticas representativas de otros pueblos y grupos (Ibídem).

Como ya apuntábamos en un análisis específico de esta norma (Autor, 2011, 21 y ss.) el patrimonio, además de ser un contenido que debía ser conocido, se abordaba como un contenido de naturaleza fuertemente actitudinal y, por eso mismo, encontramos verbos relacionados con su enseñanza que aluden a campos semánticos como el respeto, la valoración y el reconocimiento de la diversidad, la conservación, el aprecio y la mejora. Otras acciones relacionadas con contenidos de naturaleza procedimental eran referidos en la LOGSE en una frecuencia mucho menor; es el caso de la divulgación, el acceso, la localización, la protección y el goce, que sólo se mencionan en una ocasión. Esta relación de acciones y su frecuencia semántica, definían en realidad finalidades para la enseñanza del patrimonio; en todo caso, nos sitúan ante una LOGSE que orientaba la enseñanza del patrimonio hacia un marcado carácter actitudinal. Al ponderar la dimensión actitudinal de los contenidos relacionados con el patrimonio, en esencia se estaba apelando a la dimensión humana del patrimonio (Autor, 2008) y, por tanto, se aproximaba a lo que hemos venido en denominar "visión humanista de la educación patrimonial" (Autor, 2013), y que hoy en día podemos considerar como vincular, en tanto se estaba dibujando la base de un modelo apoyado en la idea de patrimonio como una serie de vínculos entre bienes y personas (Torregrosa y Falcón, 2013).

\section{La LOE: hacia un modelo completo y complejo del patrimonio en educación artística}

La presencia del patrimonio en la LOE se amplía y se expande, en tanto es abordado desde más materias, transitando hacia un enfoque más integral y holístico (Cuenca, 2002; Cuenca, 2003) que, sin olvidarse de la dimensión actitudinal, añade peso a lo conceptual y procedimental. El patrimonio se entiende más como un bien que como un valor y, por tanto, se atenúa el acento que antes se había situado en la dimensión humana -en tanto es el ser humano quien confiere valor a los bienes culturales-, y se intensifica la dimensión más material del patrimonio, tangible, si preferimos. De este modo, la educación del patrimonio se orienta a conocer, comprender, poner en valor y cuidar nuestro legado cultural.

En el capítulo II de la LOE, dedicado a la Educación Primaria, encontramos un objetivo que, aunque no explicita el término patrimonio, sí se refiere a éste en tanto se pretende conocer, comprender y respetar las diferentes culturas, las diferencias entre las personas, la igualdad de derechos y oportunidades de hombres y mujeres, así como la no discriminación de personas con discapacidad. 
En esta ley, el patrimonio va a quedar fuertemente vinculado a una de las 8 competencias básicas, concretamente a la Competencia cultural y artística, donde encontramos varios párrafos en los que se alude implícita y explícitamente al patrimonio:

Esta competencia supone conocer, comprender, apreciar y valorar críticamente diferentes manifestaciones culturales y artísticas, utilizarlas como fuente de enriquecimiento y disfrute y considerarlas como parte del patrimonio de los pueblos. (...)

La competencia artística incorpora asimismo el conocimiento básico de las principales técnicas, recursos y convenciones de los diferentes lenguajes artísticos, así como de las obras y manifestaciones más destacadas del patrimonio cultural. (...)

Implica un conocimiento básico de las distintas manifestaciones culturales y artísticas, la aplicación de habilidades de pensamiento divergente y de trabajo colaborativo, una actitud abierta, respetuosa y crítica hacia la diversidad de expresiones artísticas y culturales, el deseo y voluntad de cultivar la propia capacidad estética y creadora, y un interés por participar en la vida cultural y por contribuir a la conservación del patrimonio cultural y artístico, tanto de la propia comunidad, como de otras comunidades (LOE, 2006).

Esta alusión resulta fundamental de cara a reivindicar la importancia de la educación artística para la enseñanza del patrimonio cultural, sobre todo si tenemos presente que las competencias básicas permiten identificar aquellos aprendizajes que se consideran imprescindibles desde un planteamiento integrador y orientado a la aplicación de los saberes adquiridos. Su logro deberá capacitar a los alumnos y alumnas para su realización personal, el ejercicio de la ciudadanía activa, la incorporación a la vida adulta de manera satisfactoria y el desarrollo de un aprendizaje permanente a lo largo de la vida.

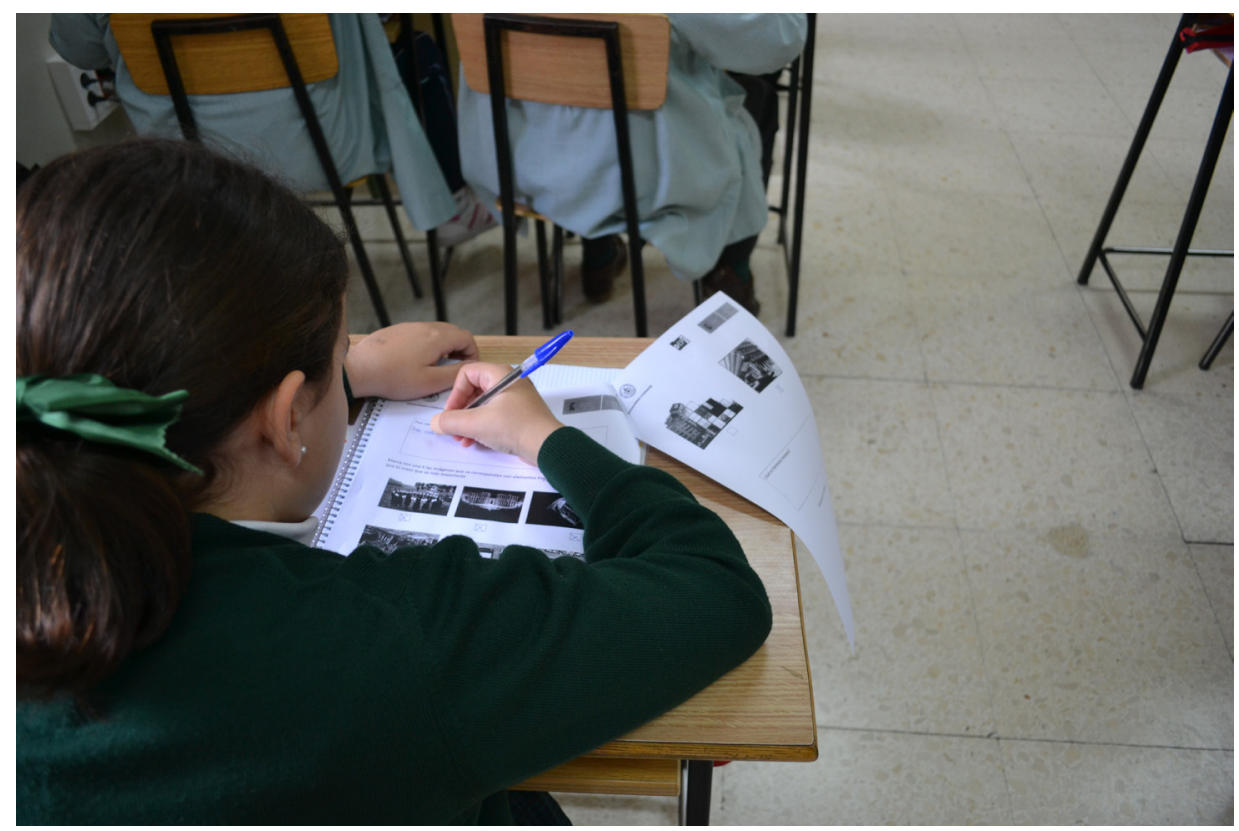

Figura 1. Alumna de Primaria aprendiendo contenidos relacionados con el Patrimonio artístico. 
En la contribución que las áreas de la etapa de Primaria hacen al desarrollo de esta competencia y de manera específica a la enseñanza del patrimonio, destaca la de Conocimiento del medio natural, social y cultural, y también el área que mayor desarrollo aporta a esta competencia, la Educación Artística. Curiosamente, lo que hoy podría entenderse como dimensión inmaterial del patrimonio, se queda prácticamente en el área de Educación Física, donde se abordan los juegos tradicionales, las actividades expresivas o la danza.

Con respecto al área de Conocimiento del medio natural, social y cultural, la contribución del área a la Competencia artística y cultural se centra en el conocimiento de las manifestaciones culturales, la valoración de su diversidad y el reconocimiento de aquellas que forman parte del patrimonio cultural. Esta definición marca, claramente, la diferencia entre lo que se consideran manifestaciones culturales y aquéllas que, dentro de éstas, forman parte del patrimonio cultural. Se está estableciendo una diferencia entre la cultura y el patrimonio cultural que implica, indirectamente, una selección, en la medida en que no todas las manifestaciones culturales son consideradas patrimonio. Por eso, implícitamente, se está aludiendo al concepto de patrimonio como selección de la cultura y sedimento de la parcela cultural (Autor, 2011, 28).

En el área de Educación Artística, encontramos un objetivo dedicado al conocimiento y valoración del patrimonio, que se sitúa en lo que hoy denominamos vínculos patrimoniales, especialmente los de propiedad y pertenencia:

6. Conocer y valorar diferentes manifestaciones artísticas del patrimonio cultural propio $y$ de otros pueblos, colaborando en la conservación y renovación de las formas de expresión locales y estimando el enriquecimiento que supone el intercambio con personas de diferentes culturas que comparten un mismo entorno (Real Decreto 1513, 2006).

En el segundo ciclo, dentro de los contenidos, el bloque 1. Observación plástica contempla el respeto y cuidado del entorno, de las obras que constituyen el patrimonio cultural, de las producciones propias y de las de los demás. En el tercer ciclo, los criterios de evaluación se refieren a la búsqueda, selección y organización de informaciones sobre manifestaciones artísticas del patrimonio cultural propio y de otras culturas, de acontecimientos, creadores y profesionales relacionados con las artes plásticas y la música.

Merece mención especial, por lo que supone de interdisciplinareidad en la concepción del patrimonio, la contribución del área de Educación física al desarrollo de la competencia cultural y artística, que se refiere a la apreciación y comprensión del hecho cultural, así como a la valoración de su diversidad, mediante el reconocimiento y la apreciación de las manifestaciones culturales específicas de la motricidad humana, tales como los deportes, los juegos tradicionales, las actividades expresivas o la danza y su consideración como patrimonio de los pueblos. 


\begin{tabular}{|c|c|c|c|}
\hline & Conceptos & Procedimientos & Actitudes \\
\hline $\begin{array}{l}\text { Real Decreto 1513/2006. } \\
\text { (Primaria) }\end{array}$ & $\begin{array}{l}\text { - Conocer. } \\
\text { - Comprender. } \\
\text { - Considerarlas como } \\
\text { parte del patrimonio } \\
\text { de los pueblos. } \\
\text { - Conocimiento básico } \\
\text { de las principales } \\
\text { técnicas, recursos } \\
\text { y convenciones } \\
\text { - Conocimiento básico (2). } \\
\text { - Aplicación de habilidades } \\
\text { de pensamiento } \\
\text { divergente. } \\
\text { - Conocimiento de las } \\
\text { manifestaciones } \\
\text { culturales (2). } \\
\text { - Valoración de su } \\
\text { diversidad. } \\
\text { - Reconocimiento de } \\
\text { aquellas que forman } \\
\text { parte del patrimonio. } \\
\text { Cultural (2). } \\
\text { - Analizar. } \\
\text { - Búsqueda, selección } \\
\text { y organización de } \\
\text { informaciones. } \\
\text { - Reconocimiento. } \\
\text { - Apreciación. } \\
\text { - Comprensión. }\end{array}$ & $\begin{array}{l}\text { - Utilizarlas como fuente } \\
\text { de enriquecimiento y } \\
\text { disfrute. } \\
\text { - Conocimiento básico de } \\
\text { las principales técnicas, } \\
\text { recursos y convenciones. } \\
\text { - Aplicación de } \\
\text { habilidades de } \\
\text { pensamiento divergente } \\
\text { y de trabajo } \\
\text { colaborativo. } \\
\text { - Cultivar la propia } \\
\text { capacidad estética } \\
\text { y creadora. } \\
\text { - Interés por participar en } \\
\text { la vida cultural. } \\
\text { - Contribuir a la } \\
\text { conservación del } \\
\text { patrimonio (2). } \\
\text { - Valoración de su } \\
\text { diversidad y el } \\
\text { reconocimiento (2). } \\
\text { - Valoración (2)). } \\
\text { - Colaborando en la } \\
\text { conservación y } \\
\text { renovación. } \\
\text { - Cuidado. } \\
\text { - Expresión. } \\
\text { - Apreciación. }\end{array}$ & $\begin{array}{l}\text { - Apreciar. } \\
\text { - Valorar críticamente. } \\
\text { - Disfrutar. } \\
\text { - Actitud abierta, } \\
\text { respetuosa y crítica } \\
\text { hacia la diversidad. } \\
\text { - Deseo y voluntad de } \\
\text { cultivar la propia } \\
\text { capacidad estética y } \\
\text { creadora. } \\
\text { - Interés por participar en } \\
\text { la vida cultural. } \\
\text { - Contribuir a la } \\
\text { conservación del } \\
\text { patrimonio. } \\
\text { - La valoración de su } \\
\text { diversidad (2) } \\
\text { - Valorándola } \\
\text { críticamente. } \\
\text { - Adoptando un } \\
\text { comportamiento en la } \\
\text { vida cotidiana de } \\
\text { defensa y recuperación. } \\
\text { - Estimando el } \\
\text { enriquecimiento que } \\
\text { supone el intercambio. } \\
\text { - Respeto. } \\
\text { - Apreciación. }\end{array}$ \\
\hline
\end{tabular}

Figura 2. Relación de términos semánticos relacionados con conceptos, procedimientos y actitudes en la LOE, Etapa de Primaria. (Fuente: Autor, 2011, 31).

Como podemos observar, el desarrollo de la educación patrimonial en la LOE se propone equilibradamente en las dimensiones conceptual, procedimental y actitudinal, aunque esta última tiene un peso ligeramente mayor. Además, la variedad terminológica permite que no se esté olvidando prácticamente ningún aspecto clave al tratar el patrimonio (Calbó, Juanola y Vallés, 2011), ofreciendo un enfoque complejo y completo, siempre transversal, de "carácter holístico, simbólico-identitario y sociocrítico, dentro de un curriculum integrado y transdisciplinar" (Cuenca, Estepa y Martín, 2011, 45).

\section{La LOMCE: el patrimonio como contenido imprescindible en una asignatura prescindible}

La Ley Orgánica 8/2013, de 9 de diciembre, para la Mejora de la Calidad Educativa, si bien ha mantenido las competencias -antes básicas, ahora clave- como elemento llave para la estructuración curricular, las ha reducido de 8 a 7 , afectando directamente a la anterior competencia cultural y artística, ahora incluida bajo la denominación sui géneris "conciencia y expresiones culturales", junto con otras como la comunicación 
lingüística, la competencia matemática y competencias básicas en ciencia y tecnología, la competencia digital, la competencia para aprender a aprender, las competencias sociales y cívicas y, finalmente, el sentido de iniciativa y espíritu emprendedor. Se adopta la denominación de las competencias clave en línea con la Recomendación 2006/962/EC, del Parlamento Europeo y del Consejo, de 18 de diciembre de 2006, y se sigue apostando por un aprendizaje por competencias que favorezca los propios procesos de aprendizaje y la motivación por aprender, debido a la fuerte interrelación entre sus componentes: el concepto se aprende de forma conjunta al procedimiento de aprender dicho concepto (Real Decreto 126, 2014).

En cuanto a las asignaturas, que se ordenan en troncales, específicas y de libre configuración autonómica, la educación artística se sitúa entre las asignaturas específicas. Dentro de éstas, dos de ellas son obligatorias, Educación física y Religión / Valores Sociales y Cívicos, dado que se han de cursar en cada uno de los cursos y, en cambio, existen otras cuatro asignaturas de entre las que los centros están obligados a ofertar al menos una de ellas: Educación Artística, Segunda Lengua Extranjera, Religión y Valores Sociales y Cívicos (estas dos últimas sólo si los padres no la han elegido en la opción anterior). Esto, en la práctica, significa que si un centro decide no ofertar la educación artística en el ejercicio de su competencia y tampoco lo hace la administración educativa autonómica en el ejercicio de las suyas propias, un alumno puede perfectamente cursar toda la educación primaria sin acceder a los contenidos propios de dicha asignatura y sin que ésta contribuya a ninguna de las 7 competencias antes descritas. En todo caso, su optatividad la sitúa en el currículum como un conocimiento menos importante, no troncal y, parece, prescindible. Este planteamiento solo sería coherente si aquello a lo que contribuye la educación artística también fuese secundario o poco importante en el desarrollo integral del niño entre los 6 y 12 años. Sin embargo, encontramos referencias a contenidos explícitos de la educación artística tanto en los principios generales, como en los objetivos de la etapa que, precisamente, por estar ubicados en estos apartados, pueden entenderse como fundamentales o generales.

Así, por ejemplo, en el artículo 6 se define como Principio general de la etapa facilitar a los alumnos y alumnas los aprendizajes de la expresión y comprensión oral, la lectura, la escritura, el cálculo, la adquisición de nociones básicas de la cultura, y el hábito de convivencia así como los de estudio y trabajo, el sentido artístico, la creatividad y la afectividad, con el fin de garantizar una formación integral que contribuya al pleno desarrollo de la personalidad de los alumnos y alumnas y de prepararlos para cursar con aprovechamiento la Educación Secundaria Obligatoria (Ibídem). La cultura, el sentido artístico y la creatividad están muy presentes en lo que puede entenderse como un párrafo base del posterior desarrollo curricular. Por eso, también entre los objetivos generales de la etapa, encontramos dos referencias claras a contenidos propios de la educación artística:

\footnotetext{
d) Conocer, comprender y respetar las diferentes culturas

(...)

j) Utilizar diferentes representaciones y expresiones artísticas e iniciarse en la construcción de propuestas visuales y audiovisuales (Ibídem).
} 
Todavía queda una posibilidad de oferta para la educación artística como parte de las asignaturas de libre configuración autonómica, que podrán ser áreas del bloque de asignaturas específicas no cursadas, áreas de profundización o refuerzo de las áreas troncales, u otras áreas a determinar. Igualmente, puede darse el caso de que la educación artística no llegue a ofertarse en toda la etapa.

Por tanto, estamos ante una contradicción o, si preferimos, falta de coherencia, cuando existen contenidos que se describen como fundamentales pero no se garantiza su adquisición, en la medida en que pueden darse casos en que no se oferten y, por tanto, no se cursen. Así, la educación artística se sitúa como una asignatura específica optativa $y$, en la medida en que pueda ser elegida como tal por el centro, como asignatura de libre configuración autonómica.

\subsection{El patrimonio en la asignatura optativa de educación artística}

Si accedemos a los contenidos específicos de este área, encontramos que la propia definición de la asignatura redunda en su carácter clave en el desarrollo del niño en esta etapa y que en esas primera líneas ya aparece referido el patrimonio:

\section{ANEXO II Asignaturas especificas}

a) Educación Artística.

Las manifestaciones artísticas son aportaciones inherentes al desarrollo de la humanidad: no cabe un estudio completo de la historia de la humanidad en el que no se contemple la presencia del arte en todas sus posibilidades. Por otra parte, el proceso de aprendizaje en el ser humano no puede estar alejado del desarrollo de sus facetas artísticas que le sirven como un medio de expresión de sus ideas, pensamientos y sentimientos. Al igual que ocurre con otros lenguajes, el ser humano utiliza tanto el lenguaje plástico como el musical para comunicarse con el resto de seres humanos. Desde esta perspectiva, entender, conocer e investigar desde edades tempranas los fundamentos de dichos lenguajes va a permitir al alumnado el desarrollo de la atención, la percepción, la inteligencia, la memoria, la imaginación y la creatividad. Además, el conocimiento plástico y musical permitirá el disfrute del patrimonio cultural y artístico, al valorar y respetar las aportaciones que se han ido añadiendo al mismo (Real Decreto 126, 2014).

Por lo tanto, estamos ante una asignatura que permitirá a los alumnos abordar un estudio completo de la humanidad en tanto las manifestaciones artísticas son inherentes a ella y lo son además teniendo en cuenta la gran variabilidad de posibilidades expresivas. Además, el arte se entiende como un vehículo para el desarrollo de ideas, pensamientos y sentimientos a través de un lenguaje que nos sirve para comunicarnos. El conocimiento y experimentación con estos lenguajes permite el desarrollo de procesos cognitivos como la atención y la percepción o la memoria y estimula la creatividad e imaginación, todas ellas entendidas como formas de inteligencia. Encontramos una clara referencia al patrimonio cultural y artístico en términos de disfrute, respeto y valoración, que son solo el inicio de una fuerte presencia del patrimonio en este área que, recordemos, puede no ser cursada. Resulta complicado aceptar que semejantes aportaciones lleguen a ser optativas en el desarrollo de la estructura curricular.

Sabemos que en el sistema de distribución de competencias de la LOMCE, corresponde al Gobierno determinar los estándares de aprendizaje evaluables. Por su 
parte, las Administraciones educativas autonómicas podrán establecer los bloques de contenidos tanto si se trata de una asignatura específica como si es de libre configuración autonómica. Y podrán también fijar el horario correspondiente a ambos tipos de asignaturas. Finalmente, será competencia de los centros complementar los contenidos de la educación artística, como de todas las demás asignaturas, diseñar e implantar métodos pedagógicos y didácticos propios y, también, determinar la carga horaria correspondiente a las diferentes asignaturas.

Entrando en el terreno de los contenidos, el área de Educación Artística se divide en dos partes: la Educación Plástica, y la Educación Musical, y ambas dedican parte de sus contenidos al patrimonio cultural. Así, dentro del desarrollo de la educación artística, el bloque 2, centrado en la expresión artística, sitúa como el $6^{\circ}$ de sus criterios de evaluación "Conocer las manifestaciones artísticas más significativas que forman parte del patrimonio artístico y cultural, adquiriendo actitudes de respeto y valoración de dicho patrimonio", desglosado en dos estándares de aprendizaje evaluables, el primero de ellos con una referencia explícita a las manifestaciones del patrimonio artístico y el segundo refiriéndose a los museos, en tanto contendores y contenidos implícitamente patrimoniales:

6.1. Reconoce, respeta y valora las manifestaciones artísticas más importantes del patrimonio cultural y artístico español, especialmente aquellas que han sido declaradas patrimonio de la humanidad.

6.2. Aprecia y disfruta las posibilidades que ofrecen los museos de conocer las obras de arte que en ellos se exponen. (Ibídem).

En este texto encontramos prácticamente completa la secuencia procedimental conocer-comprender-respetar-valorar-sensibilizar- cuidar- disfrutar-trasmitir que derivaba de la tesis de Autor (2003) y que una década después recoge el Plan Nacional de Educación y Patrimonio, situando la sensibilización como un criterio metodológico clave en este plan, porque supone un punto de inflexión entre aquellas personas que no valoran, ni cuidan el patrimonio, frente a aquellas otras que tienden a cuidarlo, a disfrutar de él y a tomar decisiones en favor de su difusión y legado. La clave la tenemos en la educación formal, entre cuyos objetivos sí está la sensibilización hacia el patrimonio pero, insistimos, en una asignatura optativa en todo caso. Por eso, en el Plan Nacional de Educación y Patrimonio se plantean dos secuencias dentro de este proceso hacia la sensibilización: $1^{\circ}$ Conocer para comprender, comprender para valorar y $2^{\circ}$. Valorar para cuidar, cuidar para conservar, conservar para transmitir (Domingo, Autor y Ballesteros, 2013, 15-16). En este sentido, es importante recordar que los Planes Nacionales de Patrimonio Cultural son instrumentos de gestión de los bienes culturales que se crean en los 80 del s. XX., que parten de la necesidad de consenso de criterios y metodología de intervención en los mismos, y se sustentan en la corresponsabilización financiera de las administraciones e instituciones públicas para favorecer la protección y promoción del patrimonio cultural. Su ámbito de aplicación afecta, en este caso, a todo el territorio nacional y, además de ocuparse del ámbito formal, asumiendo como línea clave "La incorporación de la educación patrimonial como línea de desarrollo prioritario en el marco de los planes estratégicos del Ministerio de Educación, Cultura y Deporte y de las Comunidades Autónomas" (Ibídem). 
Volviendo a los contenidos de la Educación Artística, también la parte de Educación Musical, en su primer bloque, centrado en la escucha, señala como tercer criterio de evaluación "Conocer ejemplos de obras variadas de nuestra cultura y otras para valorar el patrimonio musical conociendo la importancia de su mantenimiento y difusión aprendiendo el respeto con el que deben afrontar las audiciones y representaciones", derivando a un criterio de evaluación una referencia más indirecta a la cuestión patrimonial: "3.2. Comprende, acepta y respeta el contenido de las normas que regulan la propiedad intelectual en cuanto a la reproducción y copia de obras musicales" (Real Decreto 126, 2014).

En el tercer bloque, dedicado a la música, el movimiento y la danza, encontramos un primer criterio de evaluación centrado en la adquisición de capacidades expresivas y creativas que ofrecen la expresión corporal y la danza, valorando su aportación al patrimonio y disfrutando de su interpretación como una forma de interacción social, con reflejo en un estándar de aprendizaje que señala el conocimiento de danzas de distintas épocas y lugares; en todo caso, se está valorando su aportación al patrimonio artístico y cultural.

Por tanto, la educación artística se ocupa en la LOMCE del patrimonio artístico y cultural en algo tan importante como la sensibilización de los alumnos, lo que dota a esta materia de un carácter clave en el aprendizaje y apropiación simbólica del patrimonio cultural, sostenida sobre un enfoque centrado en las actitudes y en los vínculos entre bienes y personas, que estará también presente en otras materias, aunque con matices sustantivos, como veremos a continuación.

\subsection{El patrimonio cultural en las asignaturas troncales de Educación Primaria}

Ciencias Sociales, por una parte y Lengua Castellana y Literatura, por otra, son las dos asignaturas troncales que se ocupan del patrimonio cultural en diferentes aspectos.

Así, en la definición de la asignatura de Ciencias Sociales, se plantea la importancia de que el alumnado desarrolle la curiosidad por conocer las formas de vida humana en el pasado y que valore la importancia que tienen los restos para el conocimiento y estudio de la historia, como patrimonio cultural que hay que cuidar y legar. En este bloque también se desarrolla la capacidad para valorar y respetar el patrimonio natural, histórico, cultural y artístico, asumiendo las responsabilidades que supone su conservación y mejora.

Se insiste, por tanto, en la dimensión histórica y se vuelve a incidir en acciones como el conocimiento, el estudio, la valoración, el respeto y la responsabilización en el devenir del legado histórico y cultural. En la tabla resumen de contenidos CCSS, será en el Bloque 4. Las huellas del tiempo, donde encontremos el grueso de contenidos dedicados al patrimonio: 


\begin{tabular}{|c|c|c|}
\hline Contenidos & Criterios de evaluación & Estándares de aprendizaje evaluables \\
\hline \multicolumn{3}{|c|}{ Bloque 4. Las huellas del tiempo } \\
\hline \begin{tabular}{|l|} 
El tiempo histórico y su medida. \\
Las fuentes históricas y su clasificación. \\
Las Edades de la Historia: Duración y datación \\
de los hechos históricos significativos que las \\
acotan. Las lineas del tiempo. \\
La Peninsula Ibérica en la Prehistoria. \\
La Peninsula Ibérica en la Edad Antigua. \\
Los Reinos Peninsulares en la Edad Media. \\
La Monarquia Hispánica en la Edad Moderna. \\
España en la Edad Contemporánea (I): el siglo \\
XIX. \\
España en la Edad Contemporánea (II): los \\
siglos XX y XXI. \\
Nuestro Patrimonio histórico y cultural.
\end{tabular} & $\begin{array}{l}\text { 1. Explicar las caracteristicas de cada tiempo histórico y ciertos } \\
\text { acontecimientos que han determinado cambios fundamentales } \\
\text { en el rumbo de la historia. } \\
\text { 2. Utilizar las nociones básicas de sucesión, duración y } \\
\text { simultaneidad para ordenar temporalmente algunos hechos } \\
\text { históricos y otros hechos relevantes. } \\
\text { 3. Identificar y localizar en el tiempo y en el espacio los procesos } \\
\text { y acontecimientos históricos más relevantes de la historia de } \\
\text { España para adquirir una perspectiva global de su evolución. } \\
\text { 4. Desarrollar la curiosidad por conocer las formas de vida } \\
\text { humana en el pasado, valorando la importancia que tienen los } \\
\text { restos para el conocimiento y estudio de la historia y como } \\
\text { patrimonio cultural que hay que cuidar y legar. } \\
5 \text {. Valorar la importancia de los museos, sitios y monumentos } \\
\text { históricos como espacios donde se enseña y se aprende } \\
\text { mostrando una actitud de respeto a su entorno y su cultura, } \\
\text { apreciando la herencia cultural. }\end{array}$ & 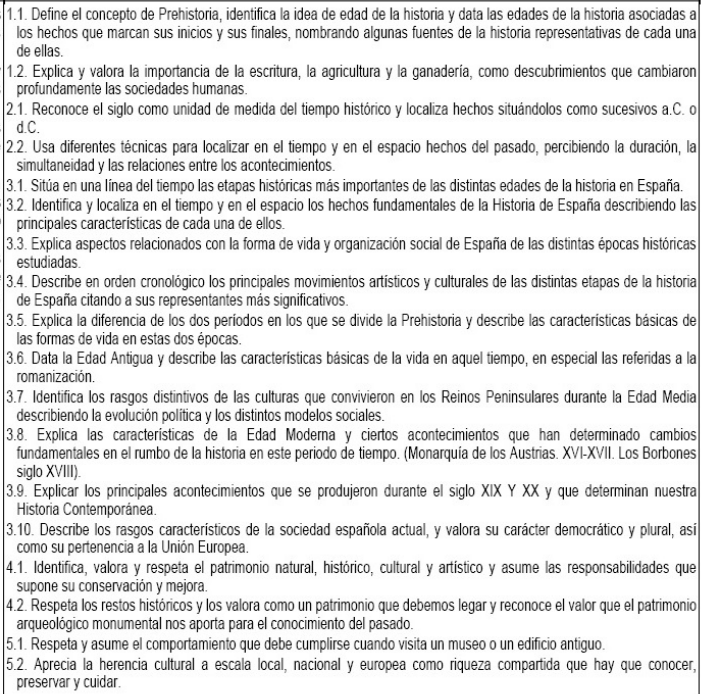 \\
\hline
\end{tabular}

Figura 3. Tabla resumen de contenidos CCSS (Fuente: BOE 52, 1/03/2014, Pag. 19377).

Es importante el uso de pronombre posesivo "nuestro", al hacer referencia al Patrimonio histórico y cultural (último de los contenidos del bloque) y, también, que en el cuarto de los criterios de evaluación se sitúe la importancia de desarrollar la curiosidad por conocer las formas de vida humana en el pasado, valorando la importancia que tienen los restos para el conocimiento y estudio de la historia y como patrimonio cultural que hay que cuidar y legar. Por eso, los estándares de aprendizaje evaluables desglosan este criterio en 4:

4.1. Identifica, valora y respeta el patrimonio natural, histórico, cultural y artístico y asume las responsabilidades que supone su conservación y mejora.

4.2. Respeta los restos históricos y los valora como un patrimonio que debemos legar $y$ reconoce el valor que el patrimonio arqueológico monumental nos aporta para el conocimiento del pasado.

5.1. Respeta y asume el comportamiento que debe cumplirse cuando visita un museo o un edificio antiguo.

5.2. Aprecia la herencia cultural a escala local, nacional y europea como riqueza compartida que hay que conocer, preservar y cuidar (Real Decreto 126, 2014).

En lo que respecta a la asignatura de Lengua Castellana y Literatura, también será el cuarto bloque, Conocimiento de la lengua, el más centrado en la enseñanza del patrimonio cultural inmaterial, en tanto se sitúa como contenido el conocimiento general de realidad plurilingüe de España y su valoración como fuente de enriquecimiento personal, entendido como una muestra de la riqueza de nuestro patrimonio histórico y cultural. A ello se orienta precisamente el sexto de los criterios de evaluación, aunque no explicita el propio término patrimonio, que sí se retoma en los estándares de aprendizaje 
6.1. Conoce y valora la variedad lingüística de España y el español de América. 6.2 Reconoce e identifica algunas de las características relevantes (históricas, socioculturales, geográficas y lingüísticas) de las lenguas oficiales en España.

\section{Conclusiones: la rentabilidad de la educación patrimonial}

Conocer la evolución que ha tenido el patrimonio en el área de educación artística a través de los textos curriculares de las tres últimas décadas nos permite tomar conciencia de varias cuestiones:

\section{Existe una estrecha vinculación entre educación artística y patrimonio en la Educación Primaria.}

Tal y como nos muestra el análisis del contenido de los textos curriculares de esta etapa, el área de educación artística se ha ocupado, en la Etapa de Primaria, del patrimonio desde la LOGSE, pasando por la LOE hasta la actual LOMCE. Si comenzó hace 30 años asumiendo una dimensión actitudinal en la enseñanza del patrimonio, continuo con una visión completa, compleja y holística, para acercarse a los procesos de sensibilización en el currículum actual donde, sin embargo, no goza de un carácter obligatorio. En todo caso, ha sido y es una de las materias, junto con las Ciencias Sociales, que mayor responsabilidad tiene en el desarrollo de este contenido, al menos en la normativa curricular. Cabe reflexionar, de manera crítica, sobre las incongruencias que presenta el currículum actual, cuando otorga contenidos esenciales para el desarrollo integral de los alumnos -entre ellos el patrimonio cultural- a una asignatura cuya impartición es optativa.

2. La formación de maestros debe incluir la formación en educación patrimonial

La propia formación inicial del profesorado no aborda por lo general el patrimonio como un referente clave en los procesos de enseñanza y aprendizaje dentro de sus programas universitarios, manteniéndose un vacío respecto al aprovechamiento educativo de unos referentes didácticos que podrían estructurar la formación en el ámbito sociohistórico y natural (González-Monfort, 2011, 57). En este sentido, la disciplina o área universitaria de Didáctica de la Expresión Plástica, en tanto se imparte en Facultades de Educación en las que se forma a los maestros de E. Primaria, puede ocuparse del patrimonio en los contenidos disciplinares que se han de impartir en las asignaturas del área. En este sentido, actualmente contamos con, al menos, 9 universidades españolas donde existe una asignatura optativa relacionada con la didáctica del patrimonio/museos y, al menos, 23 titulaciones que contemplan, entre los contenidos de las asignaturas del área, aspectos relacionados con el patrimonio cultural. 


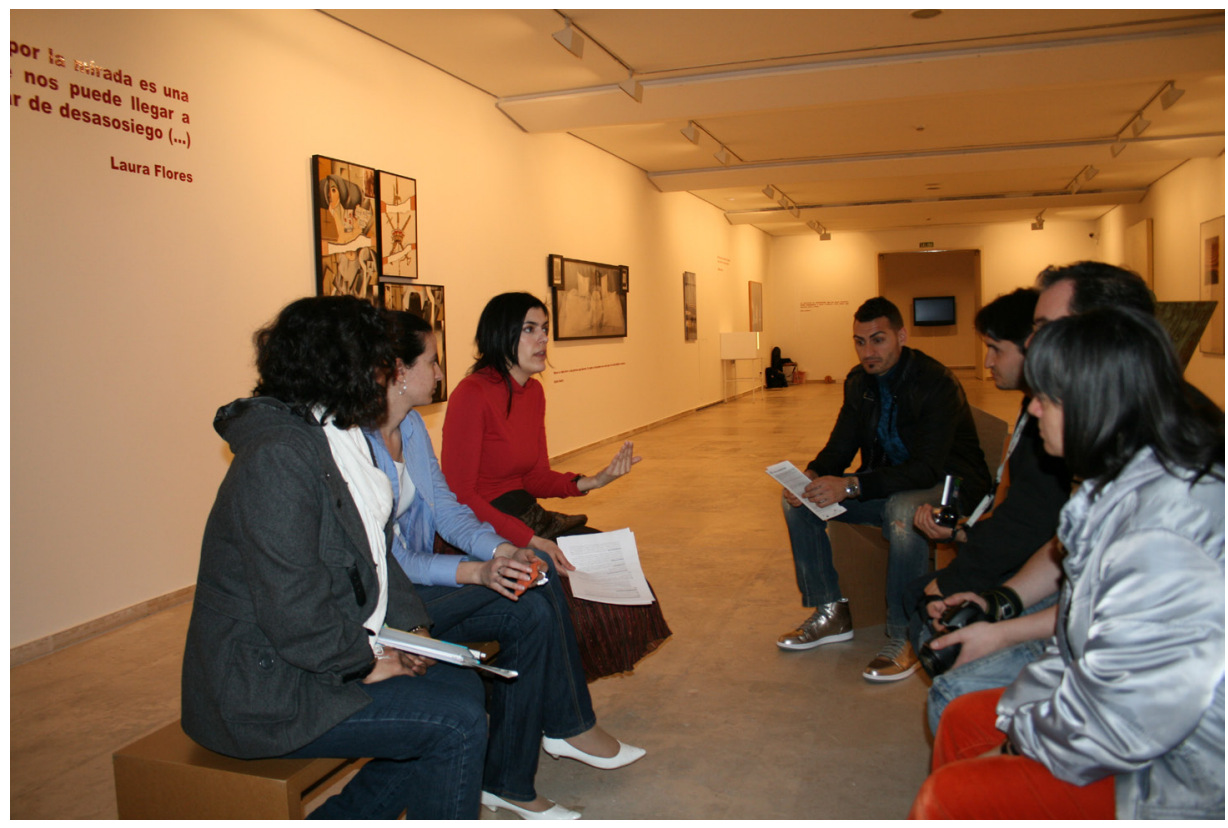

Figura 4. Alumnos de la Facultad de Educación (Uva) aprenden patrimonio artístico en el Museo Patio Herreriano.

\section{El área universitaria de Didáctica de la Expresión Plástica ha ido consolidando una línea de investigación en educación patrimonial.}

En los últimos años se ha ido consolidando un importante campo de investigación en educación patrimonial desde el área de educación artística, donde al menos la Universidad Complutense de Madrid, la Universidad de Barcelona, la Universidad de Girona, la Universidad de Granada, la Universidad de Valencia y la Universidad de Valladolid están conformando importantes focos de investigación con, al menos, 26 tesis doctorales relacionadas con esta temática y 6 proyectos de $\mathrm{I}+\mathrm{D}+\mathrm{i}$ competitivos dirigidos en los últimos 5 años. Nos situamos, por tanto, ante una línea de investigación que se está consolidando y que, sumada a la sólida línea que ha llevado a cabo el área de Didáctica de las Ciencias Sociales, sitúa a España como una potencia internacional en educación patrimonial. Un avance importante en este área ha sido la creación del Observatorio de Educación Patrimonial en España (OEPE), sucesión de dos proyectos de I+D+i financiados por el Ministerio de Economía y Competitividad (2010-2015), cuyo cometido es localizar, inventariar, analizar y evaluar programas de educación patrimonial generados en España y el ámbito internacional en la última década. En este proyecto, liderado por una profesora de Didáctica de la Expresión Plástica, participan 6 profesores de este área, en un equipo compuesto por 20 investigadores procedentes de 9 áreas de conocimiento, de 7 universidades españolas y una francesa. 
4. El Plan Nacional de Educación y Patrimonio (PNEyP), permitirá consolidar la investigación, innovación y formación en educación patrimonial durante la próxima década.

El PNEyP, coordinado por una profesora de Didáctica de la Expresión Plástica y en cuyo equipo de expertos encontramos dos profesores de Didáctica de las Ciencias Sociales, se sitúa como un referente internacional que, además de reconocer la potencia investigadora de nuestro país, se articula a través de dos programas que permitirán, previsiblemente, la consolidación definitiva de este gran potencial. Un primer programa se ocupa de la investigación en educación patrimonial y la innovación en didáctica del patrimonio $y$, un segundo programa, se centra en la formación de agentes relacionados con la educación patrimonial en todos los ámbitos. El plan, aprobado en 2013, tiene una vigencia de al menos 10 años, pudiendo ser revisado a los 5, de manera que previsiblemente, se incrementarán y potenciarán las actuaciones en investigación, innovación y formación en educación patrimonial.

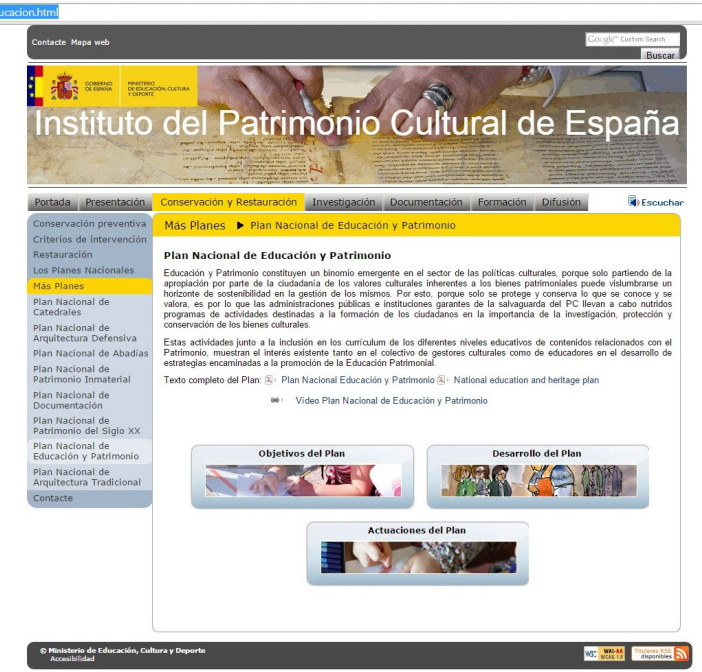

Figura 5. Web del Plan Nacional de Educación y Patrimonio. IPCE. (http://ipce.mcu.es/conservacion/planesnacionales/educacion.html).

\section{La educación patrimonial es rentable en términos sociales, culturales e identitarios.}

La educación patrimonial -en los ámbitos formal, no formal e informal- puede generar beneficios en la medida en que sucesivas generaciones vayan siendo convenientemente formadas en el conocimiento, respecto, comprensión, valorización, sensibilización, disfrute, cuidado y transmisión de sus diferentes patrimonios, individuales y compartidos, propios y ajenos. La rentabilidad social nos indica que una sociedad sensible hacia su Patrimonio está integrada por ciudadanos que sienten la necesidad de cuidar aquello que consideran que tiene valor social, dedicando esfuerzos tanto económicos como humanas a su conservación, gestión, difusión y educación. En cuanto a la rentabilidad cultural, es importante que seamos capaces de transmitir los referentes culturales 
acompañados de sus valores artísticos, estéticos, sociales o históricos (Calaf, 2009). Es decir, comprender la cultura en sus dimensiones material, inmaterial y espiritual. Por último, la rentabilidad identitaria, consecuencia de todo lo anterior, nos sitúa ante la importancia de conocer nuestros referentes identitarios, comprenderlos históricamente y ponerlos en valor de forma que, si los sentimos como propios, tenderemos a cuidarlos, preservarlos y transmitirlos. Por eso, una educación patrimonial constante, sólida y en todos los ámbitos educativos, es una garantía de solidez y seguridad identitarias.

Esta idea de rentabilidad social, cultural e identitaria debe tenerse en cuenta en un país como el nuestro, cuyo volumen de patrimonio cultural reconocido es de los mayores del mundo, con más de 60.000 Bienes de Interés Cultural (BIC) y 44 bienes incluidos en la lista de patrimonio mundial de la UNESCO.

\section{Referencias}

Calaf, R. (2009). Didáctica del patrimonio. Epistemología, metodología y estudio de casos. Gijón: Trea.

Calbó, M; Juanola, R. \& Vallés, J. (2011). Visiones Interdisciplinarias en educación del patrimonio. Girona: Documenta Universitària.

Cuenca, J. M. (2002). El patrimonio en la didáctica de las ciencias sociales: análisis de concepciones, dificultades y obstáculos para su integración en la enseñanza obligatoria. Tesis doctoral dirigida por Jesús Estepa Giménez y Consuelo Domínguez Domínguez. Universidad de Huelva.

Cuenca, J. M. (2003). Análisis de concepciones sobre la enseñanza del patrimonio en la educación obligatoria. Enseñanza de las ciencias sociales: revista de investigación, 2, 37-46.

Cuenca, J.M.; Estepa, J. Martín, M. J. (2011) El patrimonio cultural en la educación reglada. Revista de Patrimonio Cultural de España, 5, 45-58.

Cuenca, J. M. \& Estepa, J. (2013). La educación patrimonial: líneas de investigación y nuevas perspectivas. En Estepa, J. (coord.), La educación patrimonial en la escuela y el museo: investigación y experiencias (343-355). Hueva: UH.

Domingo, M; Autor. \& Ballesteros, P. (Coords.) (2013). Plan Nacional de Educación y Patrimonio. Madrid: Ministerio de Educación, Cultura y Deporte, Secretaría de Estado de Cultura.

Autor. (2003). La educación patrimonial: teoría y práctica en el aula, el museo e Internet. Gijón: Trea.

Autor. (2008). La importancia de la dimensión humana en la didáctica del patrimonio. En MATEOS, S. M. (Ed.), La comunicación global del patrimonio cultural (79110). Gijón: Trea.

Autor. (2011). El patrimonio en el marco curricular español. Revista de Patrimonio Cultural de España, 5, 21-44.

Autor. (2013). Estirando hasta dar la vuelta al concepto de patrimonio. En AUTOR. (Coord.), La educación patrimonial: del patrimonio a las personas (9-22). Gijón: Trea.

González-Monfort, N. (2011). La presencia del patrimonio cultural en los currícula de educación infantil, primaria y secundaria obligatoria en España. Revista de Patrimonio Cultural de España, 5, 59-74. 
LOE: Ley Orgánica 2/2006, de 3 de mayo, de Educación (BOE número 106 de 4/5/2006, páginas 17158 a 17207).

LOGSE: Ley Orgánica 1/1990, de 3 de octubre de 1990, de Ordenación General del Sistema Educativo (BOE número 238 de 4/10/1990, páginas 28927 a 28942).

LOMCE: Ley Orgánica 8/2013, de 9 de diciembre, para la mejora de la calidad educativa (BOE $\mathrm{n}^{\mathrm{o}} 295$ de 10/12/2013, páginas 97858 a 97921).

Real Decreto 1344/1991, de 6 de septiembre, por el que se establece el currículo de la educación primaria. (BOE_núm. 220 de_13 de septiembre de 1991, páginas 30226 a 30228).

Real Decreto 1513/2006, de 7 de diciembre, por el que se establecen las enseñanzas mínimas de la Educación primaria.(BOE número 293 de 8/12/2006, páginas 43053 a 43102).

Real Decreto 126/2014, de 28 de febrero, por el que se establece el currículo básico de la Educación Primaria. (BOE número 52 de 1/03/2014, páginas 19349 a 19420)

Torregrosa, A. \& Falcón, R. M. (2013). Patrimonios instintivos. En Huerta, R Y De La Calle, R. (coords.), Patrimonios migrantes (125-132). Valencia. UV. 